\title{
The Acquisition of Tense-Aspect: Converging Evidence From Corpora and Telicity Ratings
}

STEFANIE WULFF

University of North Texas

Department of Linguistics and

Technical Communication

P.O. Box 311307

Denton, Texas 76203-2171

Email: Stefanie.Wulff@unt.edu

\section{KATHLEEN}

BARDOVI-HARLIG

Indiana University

Department of Second Language

Studies

1021 East Third Street

Bloomington, IN 47405

Email: bardovi@indiana.edu

\author{
NICK C. ELLIS \\ University of Michigan \\ English Language Institute \\ 500 East Washington Street \\ Ann Arbor, MI 48104 \\ Email: ncellis@umich.edu
}

\author{
UTE RÖMER \\ University of Michigan \\ English Language Institute \\ 500 East Washington Street \\ Ann Arbor, MI 48104 \\ Email:uroemer@umich.edu
}

\author{
CHELSEA J. LEBLANC \\ University of Michigan \\ Department of Computer Science \\ 1200 Fairground \\ Plymouth, MI 48170 \\ Email:leblancc@umich.edu
}

The aspect hypothesis (Andersen \& Shirai, 1994) proposes that language learners are initially influenced by the inherent semantic aspect in the acquisition of tense and aspect (TA) morphology. Perfective past emerges earlier with accomplishments and achievements and progressive with activities. Although this hypothesis has been extensively studied, there have been no analyses of the frequency, form, and function of relevant types and tokens in the input. This article reports the results of 2 corpus-based studies investigating how various features of the inputfrequency distributions, reliabilities of form-function mapping, and prototypicality of lexical aspect-affect TA morphology. Study I determined the relative frequency profiles of exemplars of English TA and employed various statistics to determine the associations between particular verb-aspect combinations. Study II expanded the aspect hypothesis, examining whether native speakers judge the most frequent forms in isolation to be more prototypical in lexical aspect. Analyses were then matched against acquisition data for different TA patterns by adult learners of English (Bardovi-Harlig, 2000) to determine whether the verbs' acquisition order is determined by their frequency, form, and function in the input. Rather than testifying to the effect of 1 factor alone, the results suggest that frequency, distinctiveness, and prototypicality jointly drive acquisition.

THIS ARTICLE EXPLORES THE ACQUISITION of tense-aspect (henceforth TA) morphology from a constructionist perspective (e.g., Bates \& MacWhinney, 1987; Croft, 2001; Goldberg, 2003, 2006; Ninio, 2006; Robinson \& Ellis, 2008;

The Modern Language Journal, 93, iii, (2009)

0026-7902/09/354-369 \$1.50/0

(C)2009 The Modern Language Journal
Tomasello, 2003). The basic tenets are as follows: Language is intrinsically symbolic. It is constituted by a structured inventory of constructions as conventionalized form-meaning pairings used for communicative purposes. Constructions are of different levels of complexity and abstraction; they can comprise concrete and particular items (as in words and idioms), more abstract classes of items (as in word classes and abstract grammatical constructions), or complex combinations 
of concrete and abstract pieces of language (as in mixed constructions). The acquisition of constructions is input-driven and depends on the learner's experience of the form-function relations. It develops following the same cognitive principles as the learning of other categories, schemata, and prototypes (Cohen \& Lefebvre, 2005).

Humans can readily induce a category from experience of exemplars. Categories have graded structures (Rosch \& Mervis, 1975). Rather than all instances of a category being equal, certain instances are better exemplars than others. Exemplar theories of categorization hold that the prototype is the best example among the members of a category and serves as the benchmark against which the surrounding poorer, more borderline instances are categorized; it combines the most representative attributes of that category in the conspiracy of memorized exemplars of the class. The more similar an instance is to the other members of its category and the less similar it is to members of contrast categories, the easier it is to classify (e.g., we better classify sparrows as birds [or other average-sized, average-colored, averagebeaked, average-featured specimens] than we do birds with less common features or feature combinations, like geese or albatrosses; Tversky, 1977). The greater the token frequency of an exemplar, the more it contributes to defining the category and the greater the likelihood it will be considered the prototype of the category (Nosofsky, 1988a, 1988b; e.g., sparrows are rated as highly typical birds because they are frequently experienced examples of the category "birds").

Constructionist accounts of language acquisition thus hold that abstract constructions are learned from the conspiracy of concrete exemplars of usage following statistical learning mechanisms (Christiansen \& Chater, 2001) relating input and learner cognition. The determinants of learning include: (a) input frequency (construction frequency, Zipfian type-token frequency distributions, recency); (b) form (salience and perception); (c) function (prototypicality of meaning, importance of form for message comprehension, redundancy); and (d) interactions between these (contingency of form-function mapping) (Ellis, 2002, 2006b). Our research explores these factors in the second language acquisition (SLA) of TA morphology. We will offer empirical evidence from three distinct sources reported in the two studies presented. The first study will deal with analyses of TA in two large first language (L1) corpora and one existing crosssectional second language (L2) corpus, and the second study will examine native-speaker ratings of telicity for some of the same selected TA constructions.

Issues of TA have been of central concern in child language research for 3 decades or more, with cross-linguistic research focusing on the relationships between TA morphology and event types encoded in verb meanings, the relationships between conceptual development and language development (Ellis, 2008d; McCormack \& Hoerl, 2008), and the distribution of different constructions in the input (Gullberg \& Indefrey, 2008a, 2008b; Shirai, Slobin, \& Weist, 1998). These concerns are also central to Cognitive Linguistics (Evans, 2003). Such research has clearly established that L1 acquisition of TA morphology is influenced by the lexical semantics of verbs.

This influence of semantics on language acquisition led to an important theory of TA acquisition in terms of cognitive psychological processes of prototype formation (Andersen \& Shirai, 1994, 1996; Shirai \& Andersen, 1995). Children acquiring their mother tongue are initially influenced by the inherent semantic aspect of predicates in the acquisition of TA morphology affixed to the verbs in these predicates. They start out by using the perfective past morpheme with telic predicates (achievements and accomplishments, with a clear end point) before they extend its use to dynamic atelic predicates. Conversely, progressive marking is first used with activities before it spreads to telics. The aspect hypothesis (Andersen \& Shirai, 1994) describes how the abstract grammatical schema for perfective past generalizes from more concrete beginnings close to the prototypic center in the clear exemplifications of telic achievements and accomplishments to activities. Likewise, abstract progressive morphology emerges from concrete exemplars in the semantics of activities.

Aspect-before-tense phenomena also prevail in SLA (Andersen \& Shirai, 1994; Bardovi-Harlig, 2000; Collins, Trofimovich, White, Cardoso, \& Horst, this issue; Li \& Shirai, 2000). Adult L2 learners are sensitive to the lexical aspect of predicates, initially using combinations of lexical and grammatical aspect that are maximally compatible, with telicity (i.e., end point focus) being a particularly salient feature. Thus, L2 learners from a wide variety of L1 backgrounds and target languages first use perfective past marking on achievements and accomplishments, only later extending this to activities and states. Similarly, in L2s that have progressive morphology, marking begins with activities and extends slowly thereafter to accomplishments and achievements. 
Empirical evidence in favor of the aspect hypothesis in SLA can be found in the work of Bardovi-Harlig and Reynolds (1995) and Collins (2002), who examined cloze passages, and in the work of Bardovi-Harlig (1998, 2000), who investigated oral production data obtained from narratives. Bardovi-Harlig (2000) presented an extensive functional analysis of the acquisition of L2 TA morphology in terms of cognitive principles and semantic prototypes. In the present study of L2 TA morphology, we hypothesized that the telicity of the verbs with which particular TA morphemes are first used will be prototypical of that construction's functional interpretation.

Just as meaning is important for the development of prototypes, so too are distributional patterns in the input. We have already discussed the cognitive phenomena whereby exemplars close to the central prototype are higher in token frequency. The influence of input frequency on TA acquisition has also been investigated. Andersen $(1990,1993)$ hypothesized that the input available to learners exhibits distributional patterns similar to those observed in learners' productions; this is known as the distributional bias hypothesis. Elsewhere, Andersen and Shirai (1994) noted that "native speakers in interaction with other native speakers tend to use each verb morpheme with a specific class of verbs, also following the aspect hypothesis" (p. 137).

According to Shirai and Andersen (1995), the same is true of child-directed speech. Comprehensive reviews of such distributional biases in native speech (Shirai \& Andersen) focused on the morphological forms associated with certain semantic classes of verbs in the input, showing how the statistical tendency for past or perfective forms to occur primarily on achievements and accomplishments and for progressive forms to occur on activities could cause the learner to acquire these associations accordingly. Li and Shirai (2000) presented a connectionist simulation of such learning of TA from input using input frequency modeled after corpora in the CHILDES database.

Our present study aims to extend this work by investigating which particular verbs are associated with which grammatical forms, the contingency of the relationships (i.e., to what degree the verb-aspectual form association is one-to-one rather than one-to-many), and whether the distribution of verbs within TA construction is Zipfian (i.e., with one or a few high-frequency items accounting for the majority of exemplars of the construction as a whole). It is important to note that whereas previous studies have investigated the lexical aspect of verbs and their arguments (i.e., predicates) following traditional analyses of lexical aspect, this study investigates verbs in isolation. We wanted to be able to attribute differences in rated telicity to verb-inherent semantics (and the sense of the verb that comes to mind first) rather than to the inflected verb in interplay with its arguments or collocates.

Frequency promotes learning, and psycholinguistics demonstrates that language learners are exquisitely sensitive to input frequencies of patterns at all levels (Ellis, 2002). In the learning of categories from exemplars, acquisition is optimized by the introduction of an initial, lowvariance sample centered on prototypical exemplars (Elio \& Anderson, 1981, 1984). This low-variance sample allows learners to get a fix on what will account for most of the category members. The bounds of the category are defined later by experience of the full breadth of exemplars. Goldberg, Casenhiser, and Sethuraman (2004) demonstrated that in samples of child language acquisition, for a variety of verb-argument constructions, there is a strong tendency for one single verb to occur with very high frequency in comparison to other verbs used, a profile that closely mirrors that of the mothers' speech to these children. In natural language, Zipf's law (Zipf, 1935) describes how the highest frequency words account for the most linguistic tokens. Goldberg et al. show that Zipf's law applies within verbargument constructions too, and they argue that this promotes acquisition: Tokens of one particular verb account for the lion's share of instances of each particular argument frame; this "pathbreaking" verb also is the one with the prototypical meaning from which the construction is derived (see also Ellis \& Ferreira-Junior, this issue; Ninio, 1999, 2006). Our research investigates the generality of this claim to a different class of construction: TA morphology. Our expectation is that the verbs that first occur in a TA construction will be more frequent than others and that the distribution as a whole will be Zipfian.

Finally, whereas frequency of form is important to learning, so too is contingency of mapping (Ellis, 2006a, 2006b; Gries \& Wulff, 2005; MacWhinney, 1987). Consider how, in the learning of the category of birds, although eyes and wings are equally frequently experienced features in the exemplars, it is wings that are distinctive in differentiating birds from other animals. Wings are important features to learning the category of birds because they are reliably associated with class membership; eyes are not. Raw frequency of occurrence is less important than the contingency between cue and interpretation. For the SLA of 
TA morphology, this leads to the prediction that the verbs most distinctively associated with particular TA constructions will be acquired first.

Drawing these strands together, our research was designed to test the following hypotheses relating to the acquisition of L2 TA constructions as cognitive categories:

1. The verbs that beginning L2 learners use for each TA construction will be much more frequent in that construction in the input than the other members, and the distribution as a whole for the types constituting each construction will approximate a Zipfian distribution.

2. The verbs that beginning L2 learners use in a TA construction will be those that are more distinctively associated with that construction in the input.

3. The verbs that beginning L2 learners use in a TA construction will be prototypical of that construction's functional interpretation in terms of their lexical aspect.

To test these hypotheses, we conducted two studies, which we report here. Study I reports on an analysis of corpora comprised of native-speaker and learner production data, and Study II reports on telicity ratings of verbs by native speakers.

\section{STUDY 1: CORPUS ANALYSES}

To determine the type/token distributions and distinctiveness of association between verb and construction, we analyzed corpora of the native spoken language characteristic of input. For our analysis of beginning learner use of TA constructions, we revisited oral production data collected by Bardovi-Harlig $(1998,2000)$ from interviews with 37 beginning-level English L2 learners from five different L1 backgrounds (Arabic, Korean, Japanese, Spanish, and Mandarin).

\section{Analysis of Representative Input}

To examine frequency biases in the input, we retrieved verb form frequencies for all verbs from two native-speaker corpora: the spoken section of the British National Corpus $\left(\mathrm{BNC}_{\text {spoken }}\right)$, which contains 10 million words, and the Michigan Corpus of Academic Spoken English (MICASE; Simpson, Briggs, Ovens, \& Swales, 2002), which contains 1.7 million words. $\mathrm{BNC}_{\text {spoken }}$ includes speech events as diverse as broadcast news, parliamentary debates, and face-to-face conversations; therefore, we believe that it represents spoken language at a general level. MICASE, in contrast, is a highly specialized corpus of American English that ex-
TABLE 1

Groupings of the CLAWS 7 Tagset Categories

\begin{tabular}{ll}
\hline \hline Simple Past & Past \\
(Past and Present) Perfect & Perfect \\
(Past and Present) Progressive & Progressive \\
Simple Present & Present \\
Third Person Singular Present & \\
Infinitive & Other \\
Base (Modals) & \\
\hline
\end{tabular}

clusively comprises academic speech events like lectures, colloquia, or office hours. (It should be noted that MICASE includes a total of 201,954 words of near-native-speaker output; these were included in the present study.) In combination, we assume the two corpora to be a fair approximation of the type of language input to which L2 learners (in particular, adult learners, who learn an L2 in a college or university context) are commonly exposed. ${ }^{1}$

All verb form frequencies were retrieved from CLAWS-tagged versions of $\mathrm{BNC}_{\text {spoken }}$ and $\mathrm{MI}$ CASE, respectively (for information on CLAWS, cf. Garside \& Smith, 1997). The CLAWS 7 tagset licenses a distinction of seven TA categories, which were grouped into five classes as shown in Table 1. For the subsequent corpus analyses, items in the "other" category were disregarded. Thus, we use the term TA categories to refer to past, progressive, present, and perfect.

\section{Analysis of Learner Production Data}

This subsection addresses the question of whether, and to what extent, the verbs identified by the corpus analyses as highly frequent actually figure in the learner output in the acquisition of different TA categories. To that end, we revisited oral production data collected by BardoviHarlig (1998, 2000). She interviewed 37 English beginning L2 learners from five different L1 backgrounds, including Arabic, Korean, Japanese, Spanish, and Mandarin. Learners watched an 8minute excerpt of Modern Times twice; they were told that they would be asked to tell the story after they had seen the film. Participants met individually with an interviewer to record their narration of the plot within 30 minutes after viewing the film. The resulting narratives comprised between 11 and 175 finite verb forms, totaling 1,890 verb tokens, which amounts to an average of 51 verb tokens per narrative. All verb forms were coded for TA morphology (i.e., simple past, past progressive, pluperfect, present, present progressive, progressive without auxiliaries, present perfect, 
TABLE 2

Verbs Distinctive for Past, Progressive, and Present Tense-Aspect in Bardovi-Harlig's (1998, 2000) Data

\begin{tabular}{lllclllr}
\hline \hline & Verb & ASR & $n_{\text {learner data }}$ & Verb & ASR & $n_{\text {learner data }}$ \\
\hline PAST & say & 5.8 & 115 & PRES. & arrest & 2 & 13 \\
& see & 8.4 & 95 & & ask & 2.5 & 22 \\
& steal & 5.6 & 68 & be & 2 & 189 \\
& take & 1.9 & 81 & escape & 3.1 & 23 \\
PROG. & tell & 6.4 & 60 & have & 1.8 & 19 \\
& begin & 2.4 & 13 & make & 2.7 & 11 \\
& eat & 2.8 & 40 & run away & 3.5 & 30 \\
& run & 4.4 & 19 & sit & 2.1 & 18 \\
& sit & 3.6 & 18 & wake up & 2.4 & 15 \\
& think & 3.2 & 21 & & 5.5 & 40 \\
& walk & 8.3 & 15 & & & & \\
\hline
\end{tabular}

Note. ASR $=$ Haberman's adjusted standardized residual.

or "uninterpretable"; for a detailed description of how the verbs were coded, cf. Bardovi-Harlig, 1998).

For the purpose of the present study, we selected from this data set verbs that occurred more than 10 times overall and which were distinctly associated with present, simple past, or progressive as determined by a chi-square test (Haberman's adjusted standardized residual) had to be equal to or higher than 2). Table 2 provides an overview of these selected verbs.

\section{Results}

In this subsection we present the verb frequency distributions, the verb TA associations, and the raw frequency and association strength found in the native-speaker corpora in an attempt to identify the factors that contribute to the patterns found in the learner production data.

Verb-TA Frequencies in the Native Corpora. The first observation that can be made on the basis of the corpus data is that the verb frequency distributions across the different TA categories can be described by Zipf's law (Zipf, 1935): The frequency with which verbs occur with a certain tense-aspect category is inversely proportional to its rank in the frequency table; that is, the most frequent verb types account for the majority of all occurrences of any given TA morpheme. Figure 1 illustrates this for the 100 verbs most frequently occurring in the different TA categories (past, perfect, present, and progressive) in $\mathrm{BNC}_{\text {spoken }}$; a highly similar picture emerges from the MICASE data, as shown in Figure 2.

As noted earlier, several studies have argued in favor of the view that acquisition is driven by frequency biases in the input such that the most frequent items of a given category serve as pathbreaking items for the acquisition of the category as a whole. In the context of TA morphology, this raises the question of whether it is possible to identify verbs that occur more frequently with a particular TA morpheme than others. Tables 3 and 4 display the 10 most frequent verbs in $\mathrm{BNC}_{\text {spoken }} / \mathrm{MICASE}$ by TA category; verbs that occur among the 10 most frequent verbs in more than one TA category are highlighted in bold print. (Note that in the BNC, only 6 out of 10 verbs occur in all four TA categories; in MICASE, 3 out of 10 verbs do.)

Considering the overlap between TA categories, it seems rather unlikely that the acquisition of TA could possibly be driven solely by raw frequency of occurrence.

Verb-TA Associations in the Native Corpora. Alternatively, it has been suggested that learners are actually not only sensitive to raw cooccurrence frequencies but that they also use contingency statistics to quantify the reliability of form-function mappings and the degree to which a form is distinctive of a particular function (Ellis, 2006a, 2006b; Gries \& Stefanowitsch, 2004; MacWhinney, 1987). Thus, it could be that learners are actually not only sensitive to raw cooccurrence frequencies between forms and meaning (of verbs and TA morphemes in our example here) but also to how often a verb occurs with alternative TA morphemes and even how frequently verbs other than the one in question occur with any of the TA morphemes.

To determine which verbs are particularly associated with the progressive and the perfective more systematically than an inspection of the raw frequencies would allow for, we computed a multiple distinctive collexeme analysis (MDCA) for 
FIGURE 1

Normed Frequencies of 100 Most Frequent Verbs by Tense-Aspect Category in $\mathrm{BNC}_{\text {spoken }}$

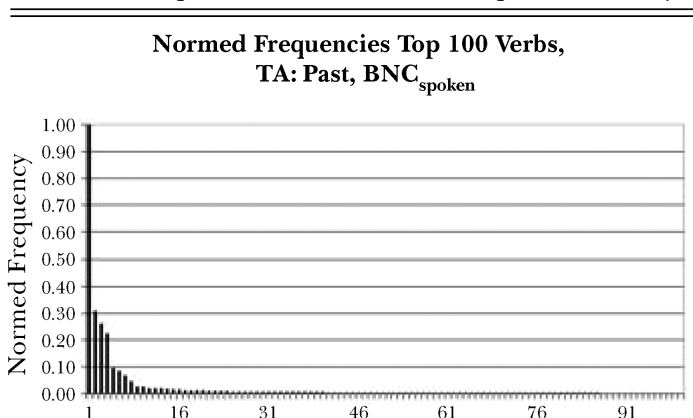

Top 100 verbs in descending order of frequency

Normed Frequencies Top 100 Verbs, TA: Perfect, $\mathbf{B N C}_{\text {spoken }}$

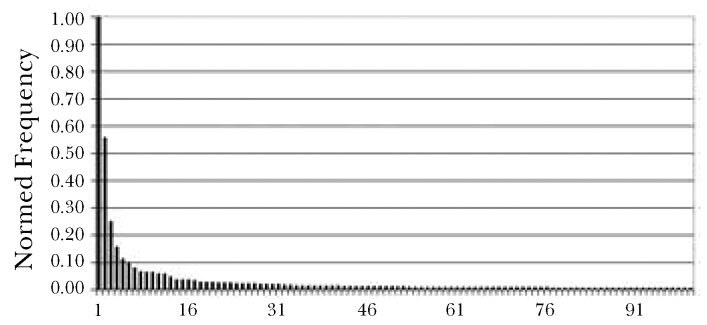

Top 100 verbs in descending order of frequency

Normed Frequencies Top 100 Verbs, TA: Progressive, $\mathbf{B N C}_{\text {spoken }}$
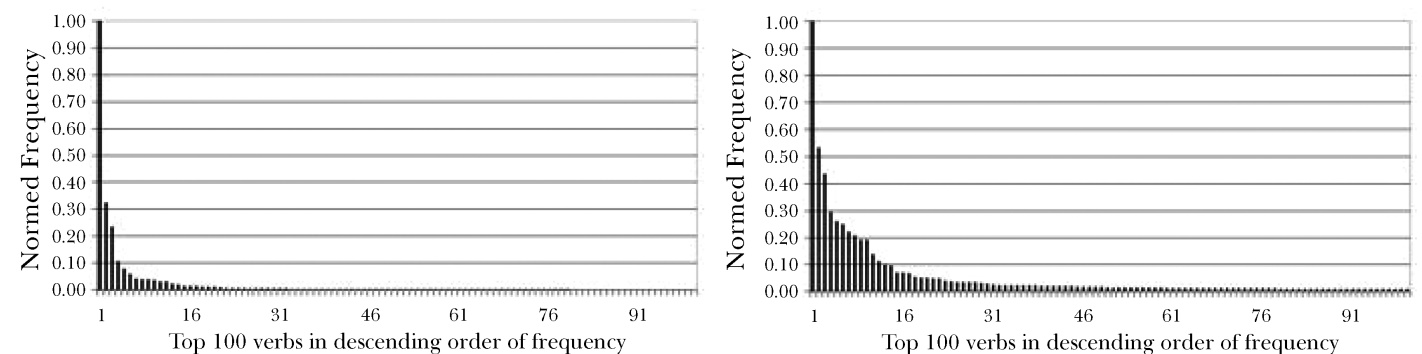

FIGURE 2

Normed Frequencies of 100 Most Frequent Verbs by Tense-Aspect Category in MICASE

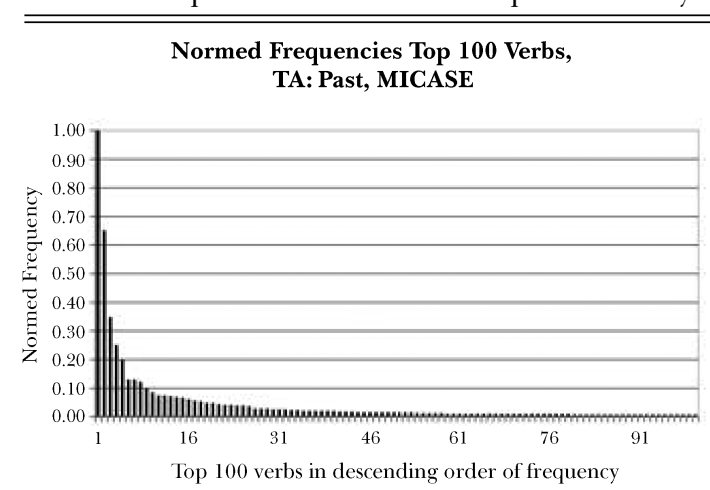

Normed Frequencies Top 100 Verbs, TA: Perfect, MICASE

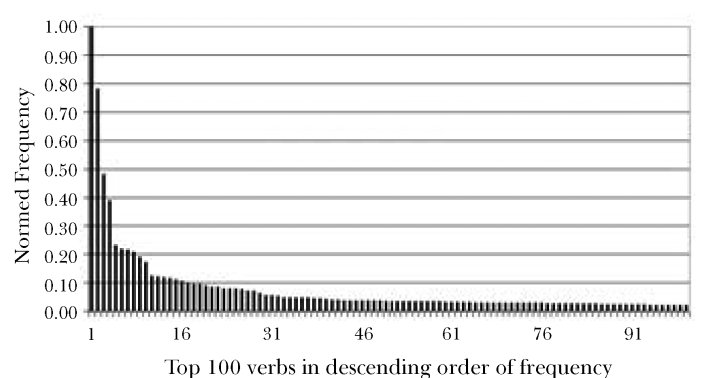

Normed Frequencies Top 100 Verbs, TA: Present, MICASE

Normed Frequencies Top 100 Verbs, TA: Progressive, MICASE
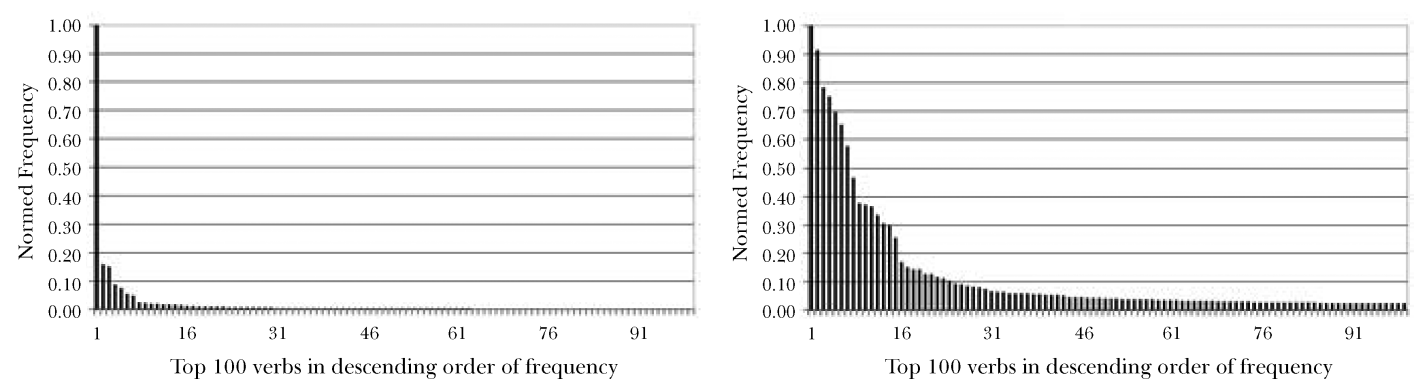
TABLE 3

The 10 Most Frequent Verbs by Tense-Aspect Category in $\mathrm{BNC}_{\text {spoken }}$

\begin{tabular}{llll}
\hline \hline Past & Perfect & Present & Progressive \\
\hline be & get & be & go \\
do & be & have & do \\
have & do & do & be \\
say & have & know & say \\
get & go & think & get \\
go & see & mean & come \\
think & make & say & have \\
come & call & go & look \\
take & take & get & talk \\
want & say & see & try \\
\hline
\end{tabular}

TABLE 4

The 10 Most Frequent Verbs by Tense-Aspect Category in MICASE

\begin{tabular}{llll}
\hline \hline Past & Perfect & Present & Progressive \\
\hline do & be & be & go \\
have & get & do & do \\
say & do & have & be \\
get & call & know & say \\
think & see & go & talk \\
want & give & think & look \\
come & use & mean & try \\
go & have & get & get \\
see & make & say & have \\
take & base & want & use \\
\hline
\end{tabular}

the $\mathrm{BNC}_{\text {spoken }}$ and MICASE data sets. MDCA is a member of the family of collostructional analyses developed by Gries and Stefanowitsch (2004). The most basic application of that family of methods is collexeme analysis, an extension of the concept of significant collocates to co-occurrences not just of two words but also of words and other linguistic elements, most notably syntactic patterns or constructions. ${ }^{2}$ Lexemes that are significantly associated with a construction are referred to as collexemes of that construction, where the association is quantified by means of the $\log$ to the base 10 of the $p$-value of the Fisher-Yates exact test (cf. Stefanowitsch \& Gries, 2003, for justification).

Multiple distinctive collexeme analysis is an extension of collexeme analysis that specifically compares two or more typically closely related or even largely synonymous constructions. Distinctive collexeme analysis has mostly been applied to look into the association between words and constructional variants, such as the dative alternation or particle placement (Gries \& Stefanowitsch, 2004). For the purposes of the present study, we use it to investigate the association between verbs and the TA morphemes with which they occur. All computations were done with Gries's $R$-script coll.analysis 3 (Gries, 2004). ${ }^{3}$ The script uses an exact binomial test to quantify the association strength between the verbs and their aspect realizations. More precisely, it provides a $p$-value for each verb with each TA morpheme and logtransforms it such that highly positive and highly negative values indicate a large degree of attraction and repulsion, respectively, and 0 indicates random co-occurrence. An (absolute) $p_{\log \text {-value }}$ that is equal to or higher than 1.3 corresponds to a probability of error of $5 \%$ or less.

One thing has to be borne in mind when interpreting the output: Because we calculated the distinctiveness of a verb across more than two categories, any given verb can theoretically be significantly associated with more than one TA category. This simply reflects the fact that most verbs occur in more than one TA category: In some, the verb occurs more often than one would expect, given the verb's corpus frequency; in others, it occurs less often than expected; and in yet other TA categories, it may occur just as often as one would predict. Accordingly, for any given verb, the MDCA provides distinctiveness values for every TA category that quantifes the deviation of expected and observed frequencies. To give one example, catch yields a $p_{\log }$-value of 2.51 for past tense, so it is significantly associated with past tense; at the same time, the $p_{\log }$-value for perfect amounts to 68.24, so catch is clearly much more distinctive for this TA category. In the following, we only report verbs as distinctive for a given TA category if that verb yielded its highest $p_{\log }$-value in that category.

Figures 3 and 4 display, in analogy to the raw frequency-based Figures 1 and 2, the top 100 most distinctive verbs in $\mathrm{BNC}_{\text {spoken }}$ and MICASE in descending order of their association strength with the different TA categories. The main point to be taken home from these graphs is that, just like the raw-frequency-based distributions, the association-based distributions are Zipfian: A small number of verbs are extremely highly associated with a particular TA category, and association strength drops exponentially within the top 100 most distinctively associated verbs. (The distributions for perfect, progressive, and, to a lesser extent, present are not as clearly Zipfian as that for past tense verbs; the difference is a matter of degree rather than quality.)

A look at the top 10 most distinctively associated verbs for each TA category (displayed in Tables 5 and 6) reveals that although verbs are distributed Zipfian-like within each category, the individual 
FIGURE 3

Normed Frequencies of 100 Most Distinctive Verbs by Tense-Aspect Category in $\mathrm{BNC}_{\text {spoken }}$

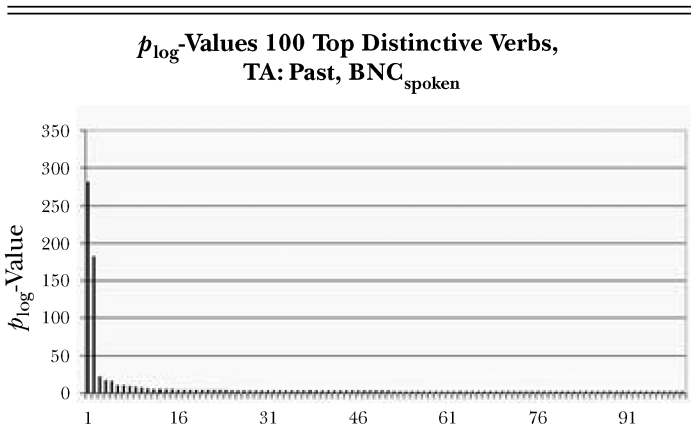

Top 100 verbs in descending order of distinctiveness

$p_{\log }$-Values 100 Top Distinctive Verbs, TA: Present, $\mathbf{B N C}_{\text {spoken }}$

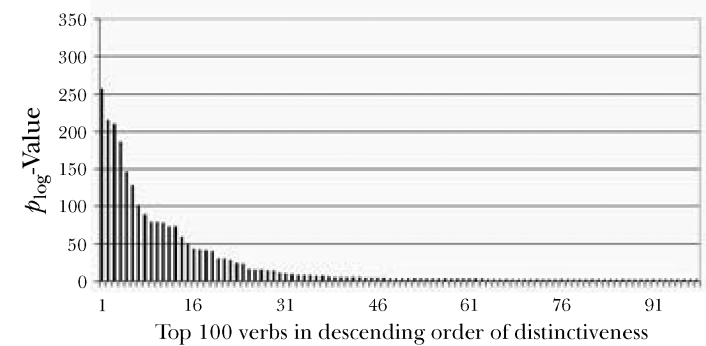

$p_{\log }$-Values 100 Top Distinctive Verbs, TA: Perfect, $\mathbf{B N C}_{\text {spoken }}$

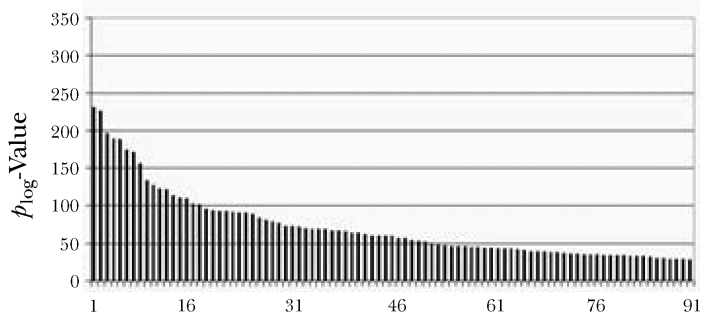

Top 100 verbs in descending order of distinctiveness

$p_{\log }$-Values 100 Top Distinctive Verbs, TA: Progressive, BNC $_{\text {spoken }}$

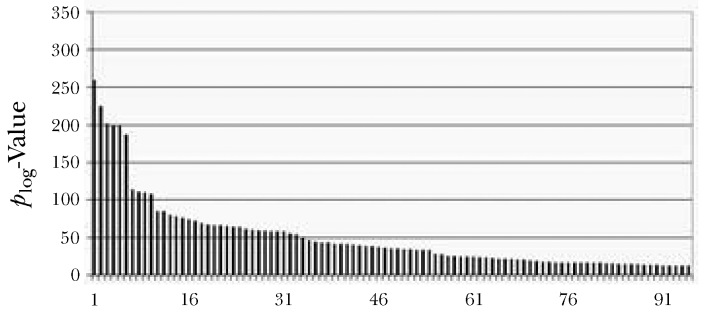

Top 100 verbs in descending order of distinctiveness

FIGURE 4

Normed Frequencies of 100 Most Distinctive Verbs by Tense-Aspect Category in MICASE

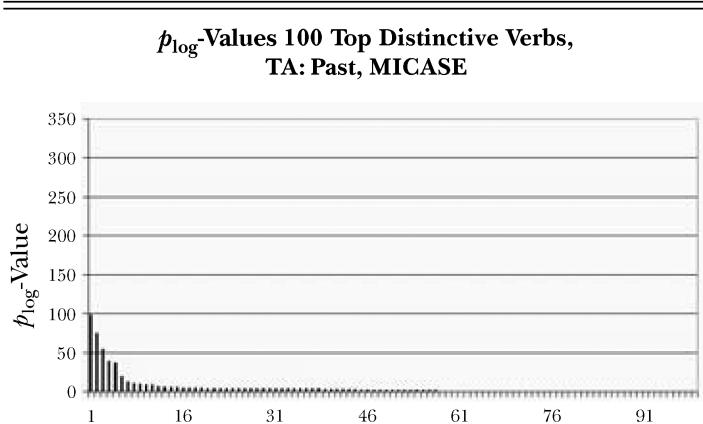

Top 100 verbs in descending order of distinctiveness

$p_{\log }$-Values 100 Top Distinctive Verbs, TA: Present, MICASE

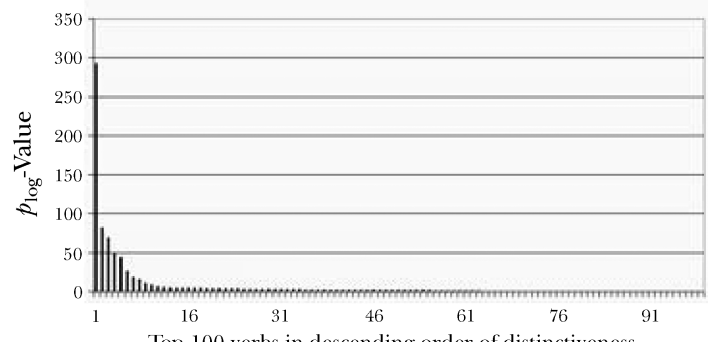

Top 100 verbs in descending order of distinctiveness $p_{\log }$-Values 100 Top Distinctive Verbs, TA: Perfect, MICASE

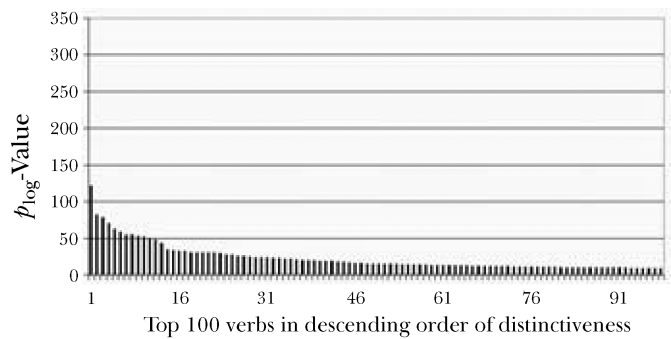

$p_{\log }$-Values 100 Top Distinctive Verbs, TA: Progressive, MICASE

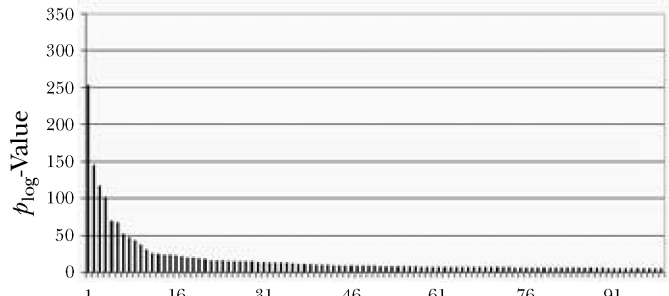

$\begin{array}{llllll}16 & 31 & 46 & 61 & 76 & 91\end{array}$

Top 100 verbs in descending order of distinctiveness 
TABLE 5

The 10 Most Distinctive Verbs by Tense-Aspect Category in $\mathrm{BNC}_{\text {spoken }}$

\begin{tabular}{llll}
\hline \hline Past & Perfect & Present & Progressive \\
\hline start & lose & suppose & look \\
die & leave & need & come \\
become & finish & want & sit \\
wake & square & bet & play \\
crash & rid & seem & wait \\
retire & allow & excuse & walk \\
panic & base & hope & joke \\
explode & bear & tend & run \\
disappear & call & reckon & watch \\
occur & marry & sound & deal \\
\hline
\end{tabular}

TABLE 6

The 10 Most Distinctive Verbs by Tense-Aspect Category in MICASE

\begin{tabular}{llll}
\hline \hline Past & Perfect & Present & Progressive \\
\hline do & call & mean & try \\
want & base & want & look \\
mention & rid & guess & work \\
happen & associate & thank & go \\
become & relate & equal & move \\
forget & bear & excuse & sit \\
begin & pay & let & wonder \\
orient & consider & suppose & deal \\
feel & square & tend & play \\
end & locate & wish & miss \\
\hline
\end{tabular}

rankings differ considerably: The MDCA identified those verbs that are distinctly associated with one TA category as opposed to the others. The rankings reflect intuitions about verbs that typically occur with the different TA categories: The past and perfect TA columns are occupied by highly telic verbs such as die, crash, explode, lose, or finish; the progressive (unsurprisingly) prefers continuous action verbs like sit, play, walk, and run.

Again, the corresponding results for MICASE confirm the basic tendencies that we observe in $\mathrm{BNC}_{\text {spoken, }}{ }^{4}$ so it appears that the results are generally robust across different speech corpora.

In contrast to simple frequencies of verb-TA cooccurrence, the association-based distribution of the verb-TA combinations highlight differences in the form-function mappings related to each TA category. Note how the association-based ranking incorporates frequency effects, only at a more elaborate level: It takes more than one out of four potentially relevant frequency values in a $2 \times 2$ matrix into account. Moreover, the resulting distri- bution is Zipfian, too, which means that a certain number of verbs are much more positively associated with a given TA category than the majority of verbs occurring with that TA. Accordingly, this characterization of the input is compatible with the assumption that a small set of highly distinctive verb-TA combinations serve as pathbreaking items in the acquisition of the TA paradigm in general.

Raw Frequency and Association Strength. Although raw frequencies and association strength tend to be highly correlated, it needs to be emphasized that they do not necessarily fully coincide. Figures 5 and 6 serve to illustrate this point, displaying-for a sample of 86 verbs that we also used for our rating experiment (to be described in detail later) - the normalized frequencies in the bottom line and the normalized

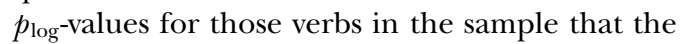
MDCA identified as being among the top 10 most distinctive verbs for progressive and past TA as corresponding dots in the upper half of the figures. (Both figures are based on $\mathrm{BNC}_{\text {spoken }}$ corpus data; normalized values are values converted to an index value ranging between 0 and 1 , the highest raw frequency being set to 1 , the lowest value 0 , and all remaining values falling in between.)

In Figure 5, we can see that the most distinctive verbs tend to come from the high-frequency band in the progressive because they cluster on the left-hand side of the graph. The corresponding Figure 6 for past tense, however, reveals a rather different picture: The overall correlation between raw frequency and the most distinctive verb-TA combinations is only moderate, more or less spreading across the whole range of cooccurrence frequencies.

\section{STUDY II: TELICITY RATINGS}

Study II investigates the prototypicality of the lexical aspect associated with individual verbs.

\section{Method}

To investigate the potential impact of prototypicality effects of the verbs involved, we obtained telicity ratings from 20 native speakers of American English for 86 verbs as listed in (1). These 86 verbs were selected because they either (a) were among the top 10 most frequent verbs in a given TA category and/or (b) had their highest $p_{\log }$-value in the TA category in question both across the two corpora and in the learner data. 
FIGURE 5

Normed Frequencies and $p_{\log }$-Values for Sample Verbs in $\mathrm{BNC}_{\text {spoken }}$ : Progressive

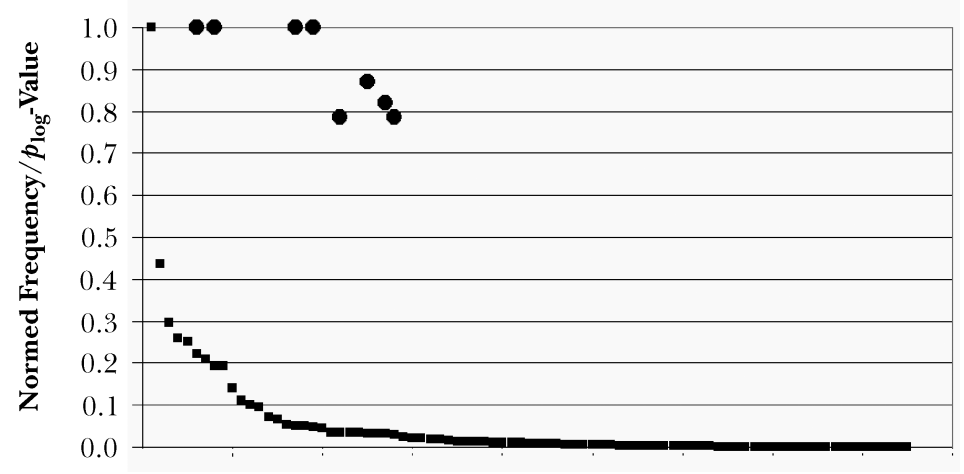

FIGURE 6

Normed Frequencies and $p_{\text {log }}$-Values for Sample Verbs in $\mathrm{BNC}_{\text {spoken }}$ : Past

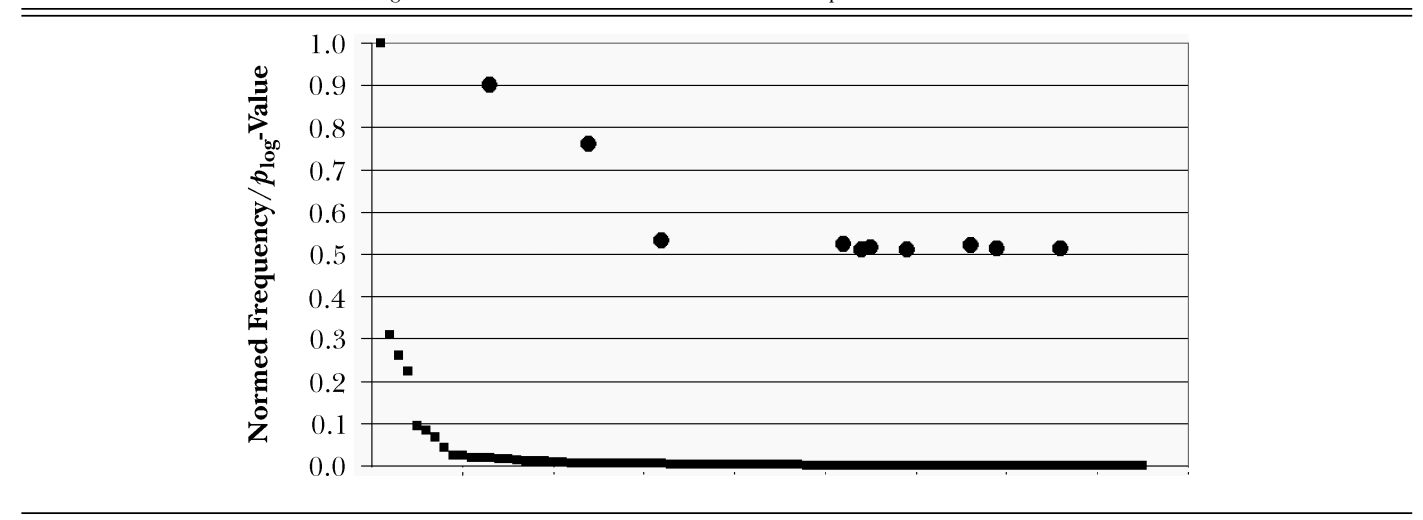

(1) affect, allow, arrest, ask, associate, assume, base, be, bear, become, begin, bet, build, call, come, connect, consider, crash, deal, die, disappear, do, eat, end, equal, escape, explode, feel, finish, forget, get, give, go, guess, hang, happen, have, hope, involve, know, leave, let, look, lose, love, make, mean, mention, move, need, notice, occur, panic, play, relate, retire, rid, run, run away, say, see, seem, set, sit, sound, stand, start, steal, suppose, take, talk, tell, tend, thank, think, try, use, wait, wake, wake up, walk, want, watch, wonder, work

Telicity ratings were elicited from 20 native speakers of American English with college or higher education using a questionnaire. The questionnaire presented the verbs in isolation, without arguments, and in their base forms. Although it has been argued that telicity is actually a property that emerges from the interplay of the lexical semantics of a verb and its argument structure, we deliberately opted for a rating that is based on the bare verb in order to be able to attribute differences in telicity to the inherent semantics of (the prototypical sense of) the verb rather than its meaning in context (Smith, 1997, e.g., adopts a compositional approach to lexical aspect and argues that verbs without arguments have inherent aspectual value). Participants were instructed to evaluate each verb with regard to how strongly it implies an end point. They were asked to imagine end point focus as a scalar concept on a continuum that could be expressed in values from 1 (no end point implied) to 7 (end point strongly implied). Three examples were given: smash as a highly telic verb, continue as an example of a verb that is located at the opposite, atelic end of the continuum, and swim as an example of a verb that falls somewhere in between.

The order of verbs was individually randomized for each questionnaire to rule out order effects, and the first five items on each questionnaire 
TABLE 7

Mean Telicity Ratings by Verb Elicited in a Questionnaire Experiment

\begin{tabular}{|c|c|c|c|c|c|c|c|c|}
\hline Verb & Mean & $S D$ & Verb & Mean & $S D$ & Verb & Mean & $S D$ \\
\hline be & 1.95 & 1.85 & talk & 3.40 & 1.50 & call & 4.85 & 1.66 \\
\hline love & 2.00 & 1.45 & consider & 3.45 & 1.54 & give & 4.85 & 1.46 \\
\hline wonder & 2.20 & 1.24 & use & 3.55 & 1.43 & bet & 4.90 & 1.45 \\
\hline hope & 2.28 & 1.45 & move & 3.60 & 1.19 & say & 5.05 & 1.32 \\
\hline seem & 2.38 & 1.16 & affect & 3.65 & 1.57 & leave & 5.10 & 2.07 \\
\hline wait & 2.38 & 1.42 & begin & 3.65 & 2.50 & wake up & 5.10 & 2.36 \\
\hline think & 2.45 & 1.36 & see & 3.80 & 1.94 & get & 5.15 & 1.90 \\
\hline want & 2.55 & 1.39 & do & 3.85 & 2.06 & set & 5.15 & 1.66 \\
\hline feel & 2.60 & 1.67 & look & 3.90 & 1.74 & forget & 5.30 & 1.69 \\
\hline try & 2.60 & 1.23 & stand & 3.90 & 1.71 & hang & 5.30 & 1.59 \\
\hline tend & 2.65 & 1.42 & equal & 4.00 & 2.20 & happen & 5.30 & 1.53 \\
\hline let & 2.75 & 1.45 & sound & 4.00 & 1.38 & take & 5.35 & 1.66 \\
\hline walk & 2.80 & 1.01 & panic & 4.10 & 1.33 & thank & 5.35 & 1.50 \\
\hline bear & 2.85 & 1.39 & start & 4.10 & 2.55 & retire & 5.40 & 2.06 \\
\hline know & 2.85 & 2.08 & ask & 4.28 & 2.02 & lose & 5.45 & 1.82 \\
\hline involve & 2.90 & 1.52 & become & 4.30 & 2.30 & rid & 5.50 & 1.57 \\
\hline have & 2.95 & 2.21 & build & 4.30 & 1.56 & arrest & 5.55 & 1.47 \\
\hline play & 3.00 & 1.45 & come & 4.35 & 1.46 & escape & 5.70 & 1.30 \\
\hline relate & 3.00 & 1.49 & deal & 4.35 & 1.60 & steal & 5.70 & 1.38 \\
\hline watch & 3.00 & 1.26 & sit & 4.35 & 1.63 & disappear & 5.95 & 1.54 \\
\hline suppose & 3.10 & 1.29 & connect & 4.45 & 1.67 & die & 6.20 & 1.91 \\
\hline work & 3.10 & 1.33 & tell & 4.45 & 1.70 & crash & 6.50 & 1.36 \\
\hline need & 3.13 & 1.52 & eat & 4.50 & 1.70 & explode & 6.50 & 1.36 \\
\hline associate & 3.15 & 1.60 & guess & 4.50 & 1.28 & end & 6.60 & 1.35 \\
\hline assume & 3.20 & 1.40 & mention & 4.50 & 1.85 & finish & 6.60 & 1.35 \\
\hline base & 3.25 & 1.65 & wake & 4.50 & 2.01 & & & \\
\hline mean & 3.25 & 1.97 & notice & 4.53 & 1.73 & & & \\
\hline allow & 3.30 & 1.34 & run away & 4.60 & 1.73 & & & \\
\hline run & 3.30 & 1.53 & make & 4.65 & 1.79 & & & \\
\hline go & 3.35 & 1.95 & occur & 4.75 & 1.92 & & & \\
\hline
\end{tabular}

tested verbs that were not among the set of the 86 true test items as a warm-up.

\section{Results}

Table 7 provides the mean telicity ratings for the verbs and their standard deviations in increasing order. As shown in Table 7, participants made use of the full range of values from 1 to 7. The results are highly reliable, as indicated by a Cronbach's alpha of .914; in other words, participants agreed nearly perfectly on which verbs rank low or high in telicity. To give a few examples, $b e$ obtained the lowest ranking (1.95), activities like work (3.10) and talk (3.40) occupy the middle ranks, lose (5.45) ranks fairly high, and finish (6.60) is assigned the highest mean telicity rating.

\section{GENERAL RESULTS}

Let us now bring corpus findings and telicity ratings together and address the question "To what extent do verbs that are distinctively associated with progressive aspect and past tense according to our corpus analyses also differ with respect to their mean telicity?" Figure 7 provides the mean telicity ratings for those groups of verbs in our sample that were identified as highly distinctive for present, progressive, perfect, and past, based on the MICASE data (on the left), $\mathrm{BNC}_{\text {spoken }}$ (in the middle), and the learner production data ( $\mathrm{KBH}$, on the right); the values are given on top of each bar.

With regard to the MICASE data, we see that past-tense-associated verbs receive significantly higher telicity ratings than verbs associated with the progressive $(t=-2.107 ; d f=18 ; p=.049)$. This difference is even more pronounced in the $\mathrm{BNC}_{\text {spoken }}$ data $(t=-4.356 ; d f=18 ; p<.001)$, and also in the learner production data $(t=$ $-2.838 ; d f=9 ; p<.01)$.

Again, the learner data suggest that association strength and inherent lexical aspect are not fully independent of frequency of occurrence: There are stable correlations between the five 
FIGURE 7

Mean Telicity Ratings for Most Distinctive Verbs by Tense-Aspect Category Across Data Sets.

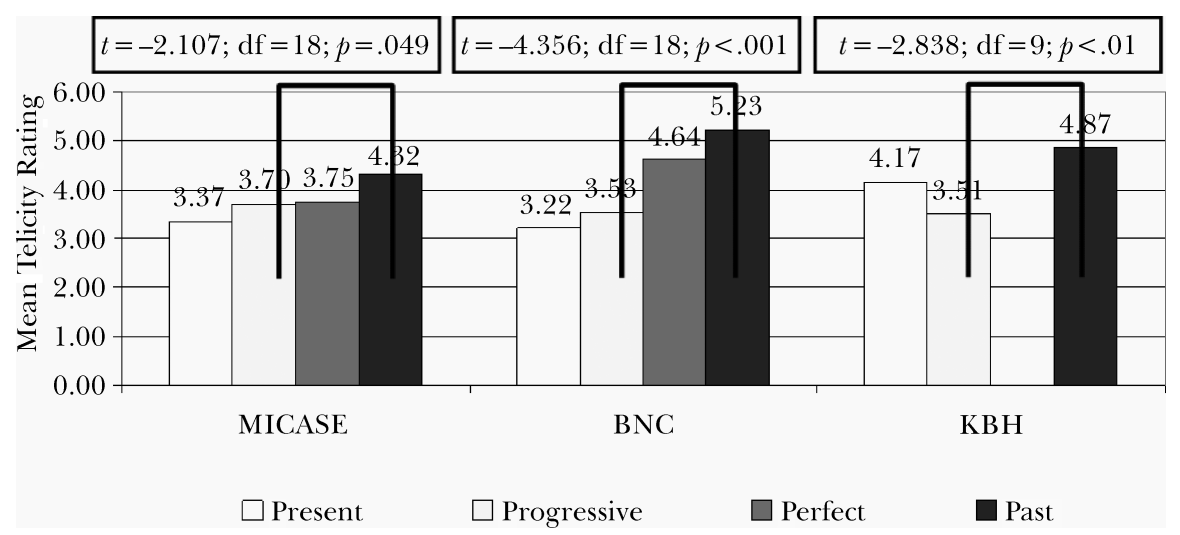

Note. BNC $=$ British National Corpus; $\mathrm{KBH}=$ learner production data; MICASE = Michigan Corpus of Academic Spoken English

most frequently occurring past tense verbs (say, see, steal, take, tell) and the five most frequently occurring progressive verbs (begin, eat, run, think, walk) and their mean telicity ratings. Although the positive correlation between use in the past tense and mean telicity does not reach statistical significance $\left(R_{\text {Pearson }}=.568 ; p=.068\right)$, the negative correlation between use in the progressive and mean telicity is highly significant $\left(R_{\text {Pearson }}=\right.$ $-.714 ; p=.014)$.

\section{CONCLUDING DISCUSSION}

These investigations of TA constructions as cognitive categories centered on four general properties of schema learning relating to input: frequency, frequency distribution, contingency of form and function, and prototypicality of function.

Our analyses of large corpora of spoken language suggest that there are indeed frequency biases in the available input whereby certain verbs are much more frequent in different TA categories and that the distribution of the verb types in the different TA categories is Zipfian. The top 10 most frequent verbs within each category are not typically distinctive of that category, however, because the highest frequency verbs in the language (like do, be, have, and get) naturally occupy the top ranks across all TA categories. Nevertheless, the MDCAs demonstrate that there are verbs that are clearly associated with the different TA constructions in the input. Furthermore, the association-based ranking of these verbs in the different TA categories is also Zipfian; that is, the most distinctive verbs for any given TA category tend to be the ones that occur more frequently in that TA category and thus could provide the category-specific input that learners need to acquire the semantic restrictions of the different TA categories.

These contingency analyses for the progressive and past categories revealed that the correlation between association strength and frequency is much higher for the progressive than for past tense. This finding may be a partial explanation for the fact that the progressive tends to be acquired earlier than past tense in L1 and L2 acquisition (Bardovi-Harlig, 2000; Brown, 1973; Dulay \& Burt, 1974; Goldschneider \& DeKeyser, 2001): The input for the progressive tends to be less noisy in the sense that the verbs most strongly associated with the progressive also tend to be the most frequent, whereas the verbs most closely related to past tense may occupy relatively lower frequency bands. The generalized conclusion, worthy of testing for other constructions, is that when distinctiveness and frequency bias coincide, this has a facilitating effect for acquisition; if, however the two are correlated only moderately, acquisition of the category in question will be more difficult.

With regard to semantics, our study has shown that the verbs most distinctively associated with progressive are judged as significantly more atelic compared to verbs that are distinctively associated with past tense. In other words, distinctiveness and frequency in the input highlight verbs that are semantically most compatible with the different TA categories. 
With regard to the question if, and to what extent, learners actually pick up on these properties of the input, our analysis of Bardovi-Harlig's $(1998,2000)$ learner data, which were not elicited with this question in mind and can consequently speak to it only within certain limitations, do lend credence to the view that learners are indeed sensitive to effects of input frequency, distinctiveness, and prototypicality of lexical aspect. Within their topical limits, the learner data suggest that the verbs first learned by adults in the progressive are also frequent in the progressive in the input, distinctively associated with the progressive in the input, and highly atelic, as defined in the rating study (i.e., significantly less telic than verbs that are frequent and associated with past tense in the input). Likewise, the verbs first learned in past tense are frequent in past tense in the input, highly distinctive for past tense in the input, and highly telic.

In terms of the general cognitive properties of schema learning, our study points to the following conclusions. First, the verbs that occur in a TA construction are those that appear frequently in that construction in the input. Second, the verbs that occur in a TA construction are distinctive of that construction-the contingency of forms and function is reliable. Third, the verbs that occur in a TA construction are those that are prototypical of the construction's functional interpretation in terms of telicity and lexical aspect. ${ }^{5} \mathrm{In}$ this study, we have demonstrated these phenomena in the learning of TA constructions. Ellis and Ferreira-Junior (this issue) demonstrate that they also apply to second language acquisition of different verb-argument constructions.

Systematic intercorrelations among item frequency, distinctiveness, and inherent lexical aspect raise two further questions. The first concerns whether any one of these factors alone could be the driving cause of learning, with the others being merely spurious confounds. The second considers how these factors come to be associated in language itself. In the discussion that follows, we consider each of these questions in turn.

Could frequency, distinctiveness, or prototypicality alone drive learning? As we described in the introduction to this article, effects of all three of these factors are standard in theories of category learning and cognition (Cohen \& Lefebvre, 2005). First, frequently experienced exemplars are better learned for the two reasons of sampling and Hebbian learning: High-frequency items are more likely to be experienced, and low-frequency items are not; once they are consolidated, access to representations and their automaticity of use is a function of their frequency of experience according to the power law of practice (Ellis, 2002, 2008b).

Second, however, as we illustrated by consideration of the information gain afforded by eyes and by wings in learning the category of birds, frequency alone is not enough. Distinctiveness or reliability of form-function mapping is a driving force of all associative learning, to the degree that the field of its study has been known as contingency learning. Rescorla (1968) showed that if one removed the contingency between the conditioned stimulus (CS) and the unconditioned stimulus (US), preserving the temporal pairing between the CS and US but adding additional trials when the US appeared on its own, then animals did not develop a conditioned response to the CS. This result was a milestone in the development of learning theory because it implied that it was contingency, not temporal pairing, that generated conditioned responding. Contingency and its associated aspects of predictive value, information gain, and statistical association have been at the core of learning theory ever since (for the case of language, see Ellis, 2008c; MacWhinney, 1987).

Third, prototypes combine the most representative attributes of a category. They are the typical instances of a category that serve as benchmarks against which the surrounding, less representative instances are classified. In the prototype theory of concepts (Rosch \& Mervis, 1975; Rosch, Mervis, Gray, Johnson, \& Boyes-Braem, 1976), for which category systems provide maximum information for the least cognitive effort, the prototype as an idealized central description is the best example of the category, appropriately summarizing the major features of relevance. The best way to teach a concept is to show an example of it. So the best way to teach a category is to show a prototypical example. However, not all categories have prototypical exemplars-what does the prototype animal look like, or the prototype thing? The average does not exist as an exemplar in real life for all categories; it does so much more for basic-level categories than for their more abstract superordinates (Murphy, 2003; Rosch et al.). When it does, it tends to occur with high token frequency.

These findings suggest a possibility for exploiting these factors in teaching: Optimal initial acquisition should occur when the central members of the category are presented early and often. For syntactic constructions, Goldberg et al. (2004) tested whether when training novel patterns (a construction of the form [Subj Obj V-o] signaling the appearance of the subject in a particular location; e.g., the king the ball moopo-ed) 
exemplified by five different novel verbs, it is better to train with relatively balanced token frequencies (4-4-4-2-2) or with a family frequency profile where one exemplar had a particularly high token frequency (8-2-2-2-2). Undergraduate native speakers of English learned this novel construction from 3 minutes of training using videos. They were then tested for the generalization of the semantics of this construction to novel verbs and new scenes.

Learners in the high token frequency condition showed significantly better learning than those in the balanced condition, a finding Goldberg (2006) has now observed in studies of child acquisition, too. However, one of the issues with prototype examples for teaching is that learners also need to go beyond the prototypes: Prototypes may provide a good initial grounding, but they can also constrain representations (Collins et al., this issue). Once established, subsequent acquisition of the full bounds of the category requires experience of the full breadth of exemplars, as discussed by Boyd and Goldberg (this issue).

We can see that the three factors frequency, distinctiveness, and prototypicality interact and that they are usually positively associated. Thus, distinguishing any one factor as the root cause of category acquisition is problematic, and probably naive. The data-driven and quantitative perspective adopted here suggests instead that, as in the acquisition of other categories, it is the conspiracy of these several different factors working together that drives acquisition of linguistic constructions.

Perhaps, indeed, it is natural that they conspire in these ways and that the functions of language in human communication have resulted in the evolution through usage of a system that optimally maps human cognition onto language form. In so doing, it results in a system that is readily acquired. Investigation of the ways in which language usage and language cognition result in learnable language structures is a much larger enterprise, and it is only at the beginning (Christiansen \& Chater, 2008; Ellis, 2008a; Ellis \& Larsen-Freeman, 2006, 2009). We can only begin to outline here how frequency, distinctiveness, and prototypicality have become associated in language and, thus, in learning.

Before they can use TA constructions productively, learners have to analyze them, to identify their linguistic form, and then map it to meaning. Each construction has its own form, meaning, and corresponding mapping pattern. Current research shows that the input that learners get is biased so that they experience past tense forms predominantly with verbs that are distinctively associated with more telic construals and progressive forms predominantly with verbs that are distinctively associated with more atelic construals. Language lines up with the world or, better, with the way we construe it. Our understanding of the world lines up with our language. Our actions in the world, our categorization of the world, and our talk about these actions and classifications occur in broadly parallel relative frequencies. These parallels make constructions learnable.

Interference with any of these aspects reduces learnability: Constructions of low salience of form are hard to learn, constructions for which there is low reliability or contingency between form and meaning are hard to learn, constructions with subtle construals yet to be discerned are hard to learn, and constructions of low frequency of occurrence tend to be acquired later (Ellis, 2008c). As causes or forces in language learning, it would be difficult, therefore, to put any of these factors first. Detailed support for these speculations awaits serious research.

Meanwhile, the findings of the present study provide empirical support for the hypothesis that the learning of tense and aspect, like that of other linguistic constructions, can be understood according to psychological principles of category learning. It is sensitive to input frequency, reliabilities of form-function mapping, and prototypicality of lexical aspect in English.

\section{NOTES}

\footnotetext{
${ }^{1}$ Many studies of input expediently investigate corpora of written language because they are easy to gather, despite the fact that spoken language is of a very different type from written language and constitutes the major part of learner experience. In this study, like Collins et al. (this issue), we chose to look at spoken data to try to restore the balance. Nevertheless, we acknowledge that at the university level, L2 learners in an L2-speaking country are also exposed to a large amount of written material. Future studies would do well to look at both the spoken and written input.

${ }^{2}$ That not only words but differently complex linguistic elements can be associated with each other systematically is one of the fundamental assumptions of Construction Grammar (Goldberg, 1995, 2006), and Gries and Stefanowitsch (2004) tailored collostructional analysis and all its extensions to precisely that assumption.

${ }^{3}$ The script is available from the author.

${ }^{4}$ Subtle differences with regard to the verbs that are most distinctively associated with the different TA categories in the two corpora reflect genre dependencies; for instance, verbs like mention, consider, and begin in
} 
Table 5 represent academic spoken English as covered in MICASE.

${ }^{5}$ Although the data considered in this study are not longitudinal or cross-sectional, considering the beginner level of our learner data invites the hypothesis that these forms are, if not the first learned, at least among those forms learned very early; future research may address this question more specifically.

\section{REFERENCES}

Andersen, R. W. (1990). Models, processes, principles and strategies: Second language acquisition inside and outside the classroom. In B. VanPatten \& J. F. Lee (Eds.), Second language acquisition-foreign language learning (pp. 45-78). Clevedon, UK: Multilingual Matters.

Andersen, R. W. (1993). Four operating principles and input distribution as explanation for underdeveloped and mature morphological systems. In K. Hyltenstam \& A. Viberg (Eds.), Progression and regression in language (pp. 309-339). Oxford: Oxford University Press.

Andersen, R. W., \& Shirai, Y. (1994). Discourse motivations for some cognitive acquisition principles. Studies in Second Language Acquisition, 16, 133156.

Andersen, R. W., \& Shirai, Y. (1996). The primacy of aspect in first and second language acquisition: The pidgin-creole connection. In W. C. Ritchie \& T. K. Bhatia (Eds.), Handbook of second language acquisition (pp. 527-570). San Diego, CA: Academic Press.

Bardovi-Harlig, K. (1998). Narrative structure and lexical aspect: Conspiring factors in second language acquisition of tense-aspect morphology. Studies in Second Language Acquisition, 20, 471-508.

Bardovi-Harlig, K. (2000). Tense and aspect in second language acquisition: Form, meaning, and use. Oxford, UK: Blackwell.

Bardovi-Harlig, K., \& Reynolds, D. W. (1995). The role of lexical aspect in the acquisition of tense and aspect. TESOL Quarterly, 29, 107-131.

Bates, E., \& MacWhinney, B. (1987). Competition, variation, and language learning. In B. MacWhinney (Ed.), Mechanisms of language acquisition (pp. 157193). Hillsdale, NJ: Erlbaum.

Boyd, J. K., \& Goldberg, A. E. (2009). Input effects within a constructionist framework. Modern Language Journal, 93, 418-429.

Brown, R. (1973). A first language: The early stages. Cambridge, MA: Harvard University Press.

Christiansen, M. H., \& Chater, N. (Eds.). (2001). Connectionist psycholinguistics. Westport, CT: Ablex.

Christiansen, M. H., \& Chater, N. (2008). Language as shaped by the brain. Behavioral Eं Brain Sciences, 31, 489-509.

Cohen, H., \& Lefebvre, C. (Eds.). (2005). Handbook of categorization in cognitive science. Mahwah, NJ: Elsevier.
Collins, L. (2002). The roles of L1 influence and lexical aspect in the acquisition of temporal morphology. Language Learning, 52, 43-94.

Collins, L., Trofimovich, P., White, J., Cardoso, W., \& Horst, M. (2009). Some input on the easy/difficult grammar question: An empirical study. Modern Language Journal, 93, 336-353.

Croft, W. (2001). Radical construction grammar: Syntactic theory in typological perspective. Oxford: Oxford University Press.

Dulay, H. C., \& Burt, M. K. (1974). Natural sequences in child second language acquisition. Language Learning, 24, 37-53.

Elio, R., \& Anderson, J. R. (1981). The effects of category generalizations and instance similarity on schema abstraction. Journal of Experimental Psychology: Human Learning E्ञ Memory, 7, 397-417.

Elio, R., \& Anderson, J. R. (1984). The effects of information order and learning mode on schema abstraction. Memory $\mathcal{E}$ Cognition, 12, 20-30.

Ellis, N. C. (2002). Frequency effects in language processing: A review with implications for theories of implicit and explicit language acquisition. Studies in Second Language Acquisition, 24, 143-188.

Ellis, N. C. (2006a). Language acquisition as rational contingency learning. Applied Linguistics, 27, 124.

Ellis, N. C. (2006b). Selective attention and transfer phenomena in SLA: Contingency, cue competition, salience, interference, overshadowing, blocking, and perceptual learning. Applied Linguistics, 27, 164-194.

Ellis, N. C. (2008a). The dynamics of second language emergence: Cycles of language use, language change, and language acquisition. Modern Language Journal, 92, 232-249.

Ellis, N. C. (2008b). Optimizing the input: Frequency and sampling in usage-based and form-focussed learning. In M. H. Long \& C. Doughty (Eds.), Handbook of second and foreign language teaching (pp. 139-158). Oxford, UK: Blackwell.

Ellis, N. C. (2008c). Usage-based and form-focused language acquisition: The associative learning of constructions, learned-attention, and the limited L2 endstate. In P. Robinson \& N. C. Ellis (Eds.), Handbook of cognitive linguistics and second language acquisition (pp. 372-405). London: Routledge.

Ellis, N. C. (2008d). Temporal cognition and temporal language the first and second times around. Commentary on McCormack and Hoerl. Language Learning, 58(Suppl. 1), 115-121.

Ellis, N. C., \& Ferreira-Junior, F. (2009). Construction learning as a function of frequency, frequency distribution, and function. Modern Language Journal, 93, 370-385.

Ellis, N. C., \& Larsen-Freeman, D. (2006). Language emergence: Implications for Applied Linguistics (Introduction to the Special Issue). Applied Linguistics, 27, 558-589.

Ellis, N. C., \& Larsen-Freeman, D. (2009). Language as a complex adaptive system. Language Learning, 59(Suppl. 1). 
Evans, V. (2003). The structure of time: Language, meaning and temporal cognition. Amsterdam: Benjamins.

Garside, R., \& Smith, N. (1997). A hybrid grammatical tagger: CLAWS4. In R. Garside, G. Leech, \& A. McEnery (Eds.), Corpus annotation: Linguistic information from computer text corpora (pp. 102-121). London: Longman.

Goldberg, A. E. (1995). Constructions: A construction grammar approach to argument structure. Chicago: Chicago University Press.

Goldberg, A. E. (2003). Constructions: A new theoretical approach to language. Trends in Cognitive Science, 7, 219-224.

Goldberg, A. E. (2006). Constructions at work: The nature of generalization in language. Oxford: Oxford University Press.

Goldberg, A. E., Casenhiser, D. M., \& Sethuraman, N. (2004). Learning argument structure generalizations. Cognitive Linguistics, 15, 289-316.

Goldschneider, J. M., \& DeKeyser, R. (2001). Explaining the "natural order of L2 morpheme acquisition" in English: A meta-analysis of multiple determinants. Language Learning, 51, 1-50.

Gries, St. Th. (2004). Coll.analysis 3: A program for R for Windows [Computer software]. Author.

Gries, St. Th., \& Stefanowitsch, A. (2004). Extending collostructional analysis: A corpus-based perspective on 'alternations.' International Journal of Corpus Linguistics, 9, 97-129.

Gries, St. Th., \& Wulff, S. (2005). Do foreign language learners also have constructions? Evidence from priming, sorting, and corpora. Annual Review of Cognitive Linguistics, 3, 182-200.

Gullberg, M., \& Indefrey, P. (2008a). Cognitive and neural prerequisites for time in language. Any answers? In M. Gullberg \& P. Indefrey (Eds.), Time to speak: Cognitive and neural prerequisites of time in language (pp. 207-216). Malvern, MA: WileyBlackwell.

Gullberg, M., \& Indefrey, P. (Eds.). (2008b). Time to speak: Cognitive and neural prerequisites of time in language. Malvern, MA: Wiley-Blackwell.

Li, P., \& Shirai, Y. (2000). The acquisition of lexical and grammatical aspect. Berlin, Germany: Walter de Gruyter.

MacWhinney, B. (1987). The competition model. In B. MacWhinney (Ed.), Mechanisms of language acquisition (pp. 249-308). Hillsdale, NJ: Erlbaum.

McCormack, T., \& Hoerl, C. (2008). Temporal decentering and the development of time concepts. Language Learning, 58(Suppl. 1), 89-113.
Murphy, G. L. (2003). The big book of concepts. Boston: MIT Press.

Ninio, A. (1999). Pathbreaking verbs in syntactic development and the question of prototypical transitivity. Journal of Child Language, 26, 619-653.

Ninio, A. (2006). Language and the learning curve: A new theory of syntactic development. Oxford: Oxford University Press.

Nosofsky, R. M. (1988a). Exemplar-based accounts of relations between classification, recognition, and typicality. Journal of Experimental Psychology: Learning, Memory, E Cognition, 14, 700-708.

Nosofsky, R. M. (1988b). Similarity, frequency, and the category representation. Journal of Experimental Psychology: Learning, Memory, EF Cognition, 14, 54 65.

Rescorla, R. A. (1968). Probability of shock in the presence and absence of CS in fear conditioning. Journal of Comparative and Physiological Psychology, 66, 1-5.

Robinson, P., \& Ellis, N. C. (Eds.). (2008). A handbook of cognitive linguistics and second language acquisition. London: Routledge.

Rosch, E., \& Mervis, C. B. (1975). Cognitive representations of semantic categories. Journal of Experimental Psychology: General, 104, 192-233.

Rosch, E., Mervis, C. B., Gray, W. D., Johnson, D. M., \& Boyes-Braem, P. (1976). Basic objects in natural categories. Cognitive Psychology, 8, 382-439.

Shirai, Y., \& Andersen, R. W. (1995). The acquisition of tense-aspect morphology. Language, 71, 743-762.

Shirai, Y., Slobin, D. I., \& Weist, R. E. (1998). Introduction: The acquisition of tense-aspect morphology. First Language, 18, 245-253.

Simpson, R. C., Briggs, S. L., Ovens, J, \& Swales, J. M. (2002). The Michigan Corpus of Academic Spoken English. Ann Arbor: The Regents of the University of Michigan.

Smith, C. (1997). The parameter of aspect (2nd ed.). Dordrecht, The Netherlands: Kluwer Academic Press.

Stefanowitsch, A., \& Gries, St. Th. (2003). Collostructions: Investigating the interaction between words and constructions. International Journal of Corpus Linguistics, 8, 209-243.

Tomasello, M. (2003). Constructing a language. Boston: Harvard University Press.

Tversky, A. (1977). Features of similarity. Psychological Review, 84, 327-352.

Zipf, G. K. (1935). The Psycho-biology of language: An introduction to dynamic philology. Cambridge, MA: MIT Press. 